\title{
BMJ Open Cohort profile for the Nurture Observational Study examining associations of multiple caregivers on infant growth in the Southeastern USA
}

\author{
Sara E Benjamin Neelon, ${ }^{1}$ Truls Østbye,${ }^{2}$ Gary G Bennett, ${ }^{3}$ Richard M Kravitz, ${ }^{4}$ \\ Shayna M Clancy, ${ }^{2}$ Marissa Stroo, ${ }^{2}$ Edwin Iversen, ${ }^{5}$ Cathrine Hoyo ${ }^{6}$
}

To cite: Benjamin Neelon SE, Østbye T, Bennett GG, et al. Cohort profile for the Nurture Observational Study examining associations of multiple caregivers on infant growth in the Southeastern USA. BMJ Open 2017;7: e013939. doi:10.1136/ bmjopen-2016-013939

- Prepublication history for this paper is available online. To view these files please visit the journal online (http://dx.doi.org/10.1136/ bmjopen-2016-013939).

Received 18 August 2016 Revised 16 December 2016 Accepted 9 January 2017

CrossMark

For numbered affiliations see end of article.

Correspondence to Dr Sara E Benjamin Neelon; sara.neelon@jhu.edu

\section{ABSTRACT}

Purpose: Childcare has been associated with obesity in children in cross-sectional and longitudinal studies, although some observed no association. Few studies have focused on care during infancy, a period when children may be especially vulnerable.

Participants: The Nurture Study is an observational birth cohort designed to assess longitudinal associations of childcare and the presence of multiple caregivers on infant adiposity and weight trajectories throughout the first year of life. We examine as potential mediators feeding, physical activity, sleep and stress. We completed recruitment in 2015. Of the 860 women who enrolled during pregnancy, 799 delivered a single live infant who met our inclusion criteria. Of those, 666 mothers $(77.4 \%)$ agreed to participate in the study for themselves and their infants.

Findings to date: Among the 666 women in the study, $472(71 \%)$ identified as black, $127(19 \%)$ as white, $7(1 \%)$ as Asian or Asian American, $6(1 \%)$ as Native American and $49(7 \%)$ as other race or more than one race; $43(7 \%)$ identified as Hispanic/Latina. Just under half $(48 \%)$ had a high school diploma or less, $61 \%$ had household incomes $<\$ 20000 /$ year and $59 \%$ were married or living with a partner. The mean (SD) infant gestational age was 41.28 weeks (2.29) and birth weight for gestational age z-score was -0.31 $(0.93)$. Just under half $(49 \%)$ of infants were females, $69 \%$ received some human milk and $40 \%$ were exclusively breast fed at hospital discharge. Data collection began in 2013 , is currently underway, and is scheduled to conclude in late 2016.

Future plans: Results will help assess the magnitude of associations between childcare in infancy and subsequent obesity. Findings will also inform intervention and policy efforts to improve childcare environments and help prevent obesity in settings where many infants spend time.

Trial registration number: Clinicaltrials.gov, NCT01788644.

\section{INTRODUCTION}

Childcare attendance has been associated with obesity and weight gain in children in
Strengths and limitations of this study

Previous cohort studies have not included sufficient representation of participants from racial or ethnic minority groups. Our cohort consists of predominately black women and infants living in the Southeastern USA.

- Results of this study will provide new information on childcare, caregivers and obesity, and may help determine associations in instances where the relationships among these variables have been unclear. Findings will also inform intervention and policy efforts to improve childcare settings and help prevent obesity in very young children.

- Our cohort includes a relatively low-income population of predominately black women. The demographic composition of our sample includes a higher representation of black women than the local population, and results from the study may not be directly generalisable to other populations. It may also limit our ability to compare findings with previous studies examining a similar research question in predominately higher income populations of women.

- A number of women withdrew from the study or could not be reached just after delivery. Consequently, bias from loss to follow-up may be an issue.

- Available funding also limited our ability to collect saliva to measure maternal and infant cortisol on the entire sample. While information on the subsample will be helpful in describing the role that stress plays in the pathway between childcare and obesity, having this information on the larger sample would be ideal.

cross-sectional and longitudinal studies in Canada, China, Denmark, the UK, the Netherlands and the USA, ${ }^{1-10}$ although some observed no association. ${ }^{11}{ }^{12}$ Most of these studies found that less formal types of care, including care by relatives and care in day-care homes, were most often associated with obesity. $^{2} 3556810$ A study in Japan and another in the USA identified grandparents 
specifically as the informal care providers most associated with obesity in children. ${ }^{5} 13$

The association between childcare and obesity may depend, in part, on the age of the children in care. Prior studies of infants, including our own work, have linked childcare in the first year of life with obesity. ${ }^{1} 2459$ Recently, we examined childcare attendance in infancy and weight outcomes at 12 months in a cohort of Danish children and found that childcare was associated with a higher body mass index z-score and increased risk of obesity at 12 months. ${ }^{1}$ Additionally, in a sample of US children, we found that any type of childcare outside of the home in the first 6 months of life was associated with greater adiposity at 12 months, and this relationship was still evident at 3 years. ${ }^{2}$

Childcare may promote the development of obesity through the provision of less healthy foods and beverages, shorter durations of breastfeeding and fewer opportunities for children to be physically active. Studies in the USA and the Netherlands found that meals and snacks served in out-of-home childcare often lacked fruits, vegetables and whole grains and included excessive fats and sugars. ${ }^{14-18}$ A study in the USA showed that non-maternal care was associated with decreased odds of continued breastfeeding. ${ }^{19}$ Studies in Canada, Australia, Scotland and the USA demonstrated that children were mostly inactive and engaged in insufficient physical activity in childcare.$^{20-25}$ Media use and screen time can also be excessive in childcare-especially in the less formal types of care. ${ }^{2627}$

Childcare may also affect obesity risk through additional pathways such as inadequate sleep, chronic stress and psychological and emotional distress. ${ }^{28} 29$ Short sleep duration has been associated with childhood obesity in numerous studies. ${ }^{29-34}$ Napping during the day while children are in childcare may delay sleep onset at night ${ }^{35} 36$ and decrease the duration and quality of night-time sleep. ${ }^{37-39}$ Childcare outside of the home has been associated with greater stress in children in a number of prior studies, ${ }^{40-42}$ and many previous studies have shown a potential link between elevated cortisol levels and obesity. ${ }^{39} 40$

For the ongoing Nurture Study, we will assess the relationship between childcare and obesity and examine specific factors that may influence this relationship, especially the role of multiple caregivers, in a sample of children from birth to 12 months of age. Assessing the impact of childcare requires us to examine all childcare providers-adults other than parents-caring for infants. Our central hypothesis is that energy intake, energy expenditure, stress and sleep, all influence the development of obesity, and that these behaviours can be modified to prevent excessive weight gain in children (figure 1). Results of this study will provide new information on childcare, caregivers and obesity, and may help determine associations in instances where the relationships among these variables have been unclear. Findings will also inform intervention and policy efforts to

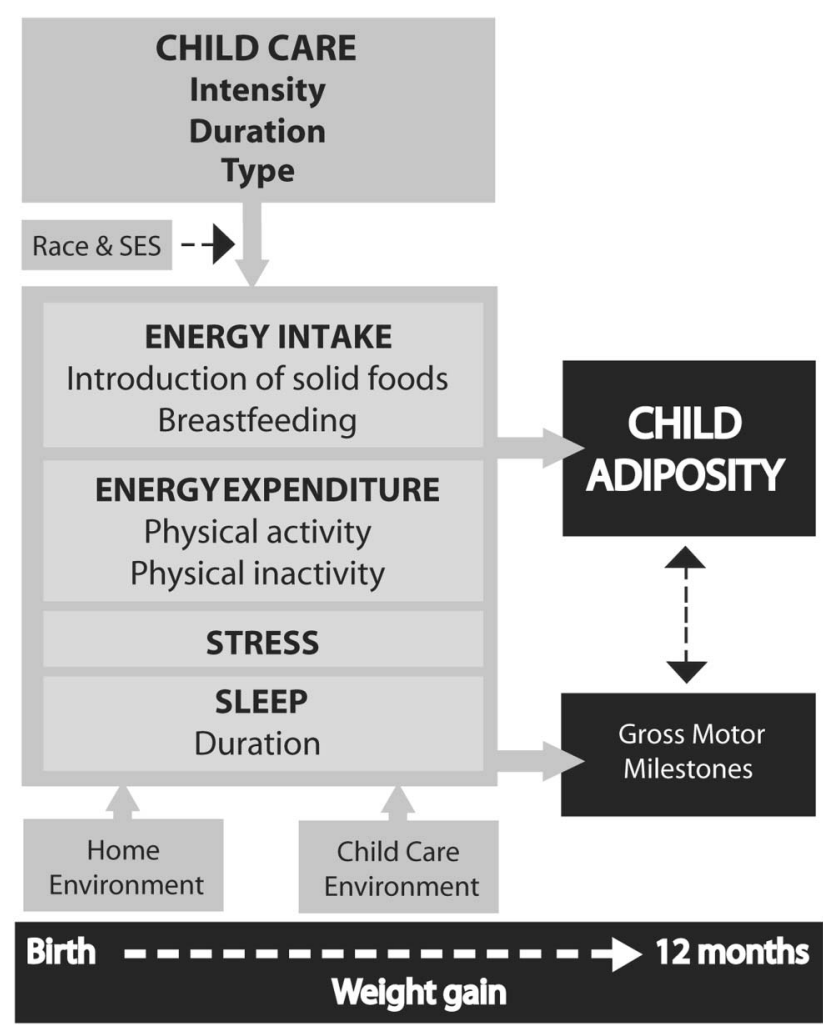

Figure 1 Nurture conceptual model.

improve the childcare system and help prevent obesity in very young children.

\section{COHORT DESCRIPTION}

Study purpose and setting

The Nurture Study is an observational birth cohort designed to assess longitudinal associations of early childcare and multiple caregivers on infant adiposity and weight trajectories throughout the first year of life. We are specifically interested in the potential mediators of feeding, physical activity, sleep and stress. The Nurture Study takes place in the Southeastern USA. We recruited and enrolled women in mid-pregnancy to latepregnancy from a private prenatal clinic and the local county health department prenatal clinic in Durham, North Carolina, USA.

\section{Study population}

To minimise attrition, pregnant women were required to be $20-36$ weeks gestation, be pregnant with a singleton with no known congenital abnormalities, be at least 18 years of age, speak and read English, intend to keep the baby and plan to stay within the area until at least 12 months post partum. Shortly after delivery, women were required to reconfirm their interest in participating in the study through a second consent process. At that time, we excluded infants who were born prior to 28 weeks gestation, had congenital abnormalities that could affect growth and development, were in the 
hospital for 3 or more weeks after birth or were not able to take food by mouth at the time of hospital discharge.

We began recruitment in 2013 and recruited our final participant in early 2015. We enrolled approximately one out of every two eligible women we approached in the prenatal clinics. Of the 860 women who enrolled during pregnancy, 799 delivered a single live infant who met our inclusion criteria. Of those, 42 withdrew from the study and 91 were lost to follow-up (unable to reach) to consent after birth, leaving a final sample size of 666 mother/infant dyads (77.4\%). Using data collected from all women at enrolment in pregnancy, we compared the 666 women included in the sample with the 133 who withdrew or were excluded. Fewer women included in the sample were Hispanic/Latina $(6.5 \%$ vs $12.0 \%, \mathrm{p}=0.04)$ and fewer were pregnant with their first child (37.0 vs 49.1, $\mathrm{p}=0.04)$. Women included were somewhat older (27.1 vs 25.9 years, $\mathrm{p}=0.02$ ) and more included women had a partner $(59.5 \%$ vs $50.0 \%$, $\mathrm{p}=0.04$ ). The included women were comparable with respect to other covariates such as prepregnancy BMI, race, education or household income.

When infants were 6 months of age, we invited, with the permission of the mother, fathers and other partners, resident (living with mother and infant) and nonresident (living elsewhere), to participate in the study. We asked all 666 women if they would like us to contact the father of the baby. Of those 666, 385 women reported that the father was involved in the baby's life and gave us permission to contact him. The remaining 281 women did not want us to contact the father of the baby about the study. Of the 385 mothers who approved and provided contact information, 271 fathers enrolled in the study. We also invited other non-parental caregivers to participate, defined as any adults who cared for infants 3 or more hours per week on a regular basis. Non-parental caregivers included family members, friends, neighbours, nannies, babysitters and childcare providers, regardless of payment for this care. We enrolled a total of 33 formal and 223 informal nonparental caregivers into the study, with an average of 1.5 per infant.

We obtained written informed consent from each woman at recruitment into the study during pregnancy and then confirmed participation of mother and infant shortly after delivery. Fathers and other caregivers provided consent to participate in the study through completion of the questionnaire.

\section{Data collection and measures}

\section{Overview}

We conducted home visits when infants were 3, 6, 9 and 12 months of age (figure 2). Each visit lasted $\sim 1.5$ hours, although the visits at 6 and 12 months could take up to 3 hours due to additional assessments. Women received automated interactive voice response (IVR) telephone calls in months 1, 2, 4, 5, 7, 8, 10 and 11 to assess a limited set of behaviours, including care-giving arrangements, infant feeding practices, infant motor milestone achievement and infant sleep (figure 2). Data collection began in 2013, is currently underway, and is scheduled to conclude in late 2016.

\section{Exposures}

Our primary exposures were infant childcare and caregiving arrangements, assessed longitudinally throughout the first year of life using questions from the Early Childhood Longitudinal Survey-Birth Cohort. ${ }^{43}$ We asked mothers to provide detailed information about any non-parental caregivers (ie, family members, friends, neighbours, nannies, babysitters and childcare providers, regardless of payment) who interacted with and cared for their infants for 3 or more hours per week on a regular basis. We assessed the type and location of care, the hours per week in each type of care and the age when care started and stopped, by month. We asked detailed questions at each home visit when infants were 3, 6, 9 and 12 months. We also asked a more abbreviated set of questions during the IVR telephone calls at months $1,2,4,5,7,8,10$ and 11 .

\section{Outcomes}

The main outcome was infant adiposity measured via weight, length and skinfold thickness at each home visit. We were also interested in infant weight trajectories over the course of the 12 months. Trained data collectors measured infant recumbent length to the nearest one-eighth inch using a ShorrBoard Portable Length Board and weight using a Seca Infant Scale to the nearest 0.1 pound. We had study scales professionally calibrated annually. We monitored the scales with calibration weights every 2 weeks to check for drift. If the weighed value deviated from the expected value more than $\pm 0.091 \mathrm{~kg}$ of the calibration weight, we had the scale professionally calibrated. Infants were weighed and measured in light clothing without shoes. We calculated age-specific and sex-specific weight-for-length z-scores using WHO reference standards. ${ }^{44}$ We measured the abdomen, subscapular and triceps skinfold thicknesses to the nearest $0.2 \mathrm{~mm}$ using standard techniques. ${ }^{45} \mathrm{We}$ used the sum of subscapular and triceps (SS+TS) skinfold thickness as a proxy for overall fatness, and the ratio of subscapular to triceps (SS:TS) skinfolds thickness as a proxy for centrally deposited fat. We conducted all assessments in triplicate and used an average of the three measurements. Body composition measures like skinfolds and weight-for-length are important anthropometric measures because they can be easily implemented in large-scale studies using portable equipment. However, these body composition measures vary in their relation to body fat mass and adiposity. ${ }^{46}{ }^{47}$ Despite these limitations, the WHO includes child growth standards for skinfolds and weight-for-length values and highlights these body composition measures as international tools for growth and nutritional assessment. ${ }^{48}$ 


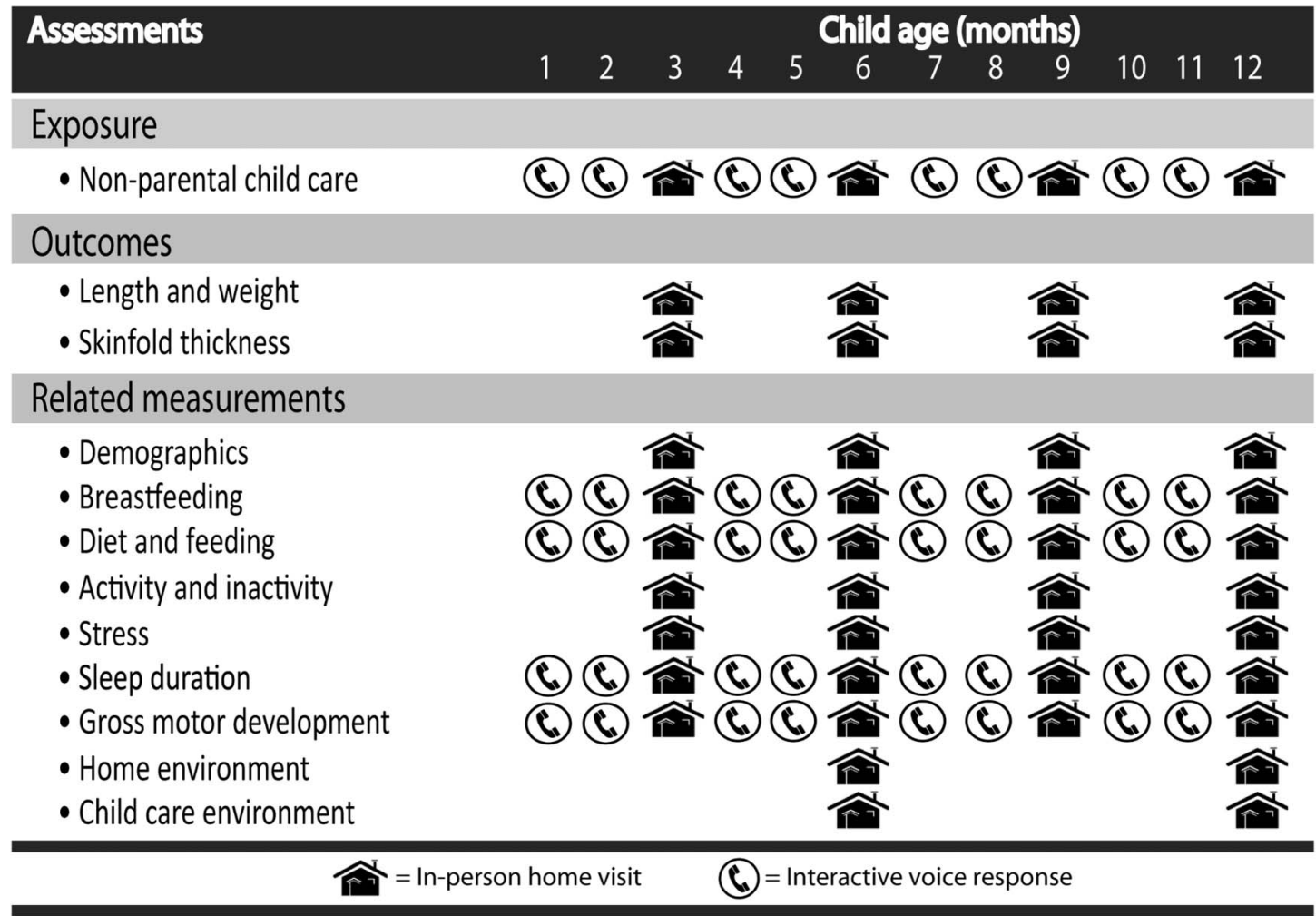

Figure 2 Nurture schedule of assessments.

Potential mediators: feeding, physical activity, sleep and stress

Feeding: Mothers reported infant feeding method as formula only, mixed feeding (some formula and some human milk) or exclusive breastfeeding and the introduction of solid foods to infants via questionnaire at each home visit and IVR call. We also asked mothers to document all foods and beverages provided to infants via questionnaire at each home visit using questions from the Infant Feeding Practices Study $\mathrm{II}^{49}$ and the Feeding Infants and Toddlers Study. ${ }^{50}$

Mothers completed the Infant Feeding Style Questionnaire (IFSQ) ${ }^{51}$ at each home visit, and fathers and caregivers completed the IFSQ at 6 and 12 months only. The IFSQ is a 63-item questionnaire that assesses infant feeding beliefs and behaviours. The IFSQ was developed by Thompson $e t a \tilde{l}^{1}$ and was tested for reliability and validity in a sample of predominately lowincome black women living in North Carolina. We measured food security status at enrolment in pregnancy and again at 3, 6, 9 and 12 months using the US Household Food Security Survey Module: Six-Item Short Form. ${ }^{52}$ Women received a food security score ranging from 0 to 6 , which we dichotomised into high or marginal food security $(0-1)$ and low food security (2-6) consistent with scoring protocol and recent literature. $^{52} 53$

Physical activity: Infants wore an ActiSleep+ device (Actigraph, Pensacola, Florida, USA) continuously on the left ankle for 4 full days (96 hours) continuously over 2 week days and 2 weekend days using a $30 \mathrm{~Hz}$ sampling rate. The ActiSleep+ is water resistant and uses a three-axis Medication Event Monitoring System (MEMS) accelerometer. Many researchers, including ourselves, have used accelerometers to assess physical activity in young children, ${ }^{54-61}$ but only a few have used these devices with infants. ${ }^{62}$ We recognise that infant movement may be generated and controlled by outside forces (eg, the mother may be carrying the infant, causing movement, but not energy expenditure in the baby); therefore, although we believe we can contribute valuable insights to physical activity through this physical activity assessment, we approach with caution. These data will provide information on infant activity to the extent possible, as the accelerometer does not specify whether an infant is engaging in movement themselves or an adult is moving the infant. The accelerometer will still, however, yield important data on infant inactivity.

Additionally, to assess infant fine and gross motor development, we conducted the Bayley Scales of Infant and Toddler Development: Third Edition ${ }^{63}$ during each home visit at 3, 6, 9 and 12 months. The Bayley Scales of Infant and Toddler Development assesses large muscle coordination, movement and balance, is tailored to the age of the infant and includes item sets corresponding to our ages for assessment. Obesity in infancy may delay achievement of gross motor milestones, and infants who attain motor milestones at later ages may be heavier or less physically active later in childhood. ${ }^{64}{ }^{65}$ We also assessed maternal report of time infants spent in 
restrictive devices (eg, car seats, strollers) via questions that the study team developed, as existing scales or assessment instruments were not available. Mothers and fathers completed the Rothbart Infant Behaviour Questionnaire, Revised Very Short Form ${ }^{66}$ when infants were 6 and 12 months to assess parents' perceptions of infant behaviour and temperament. We also asked mothers to report infant screen time using questions from the Children's Media Use in America ${ }^{67}$ at each home visit at 3, 6, 9 and 12 months.

Sleep: In addition to providing information about physical activity, the ActiSleep+ device worn by infants for 4 continuous days and nights also provides information on sleep during that time. These accelerometer data will yield average daily sleep duration, night-time sleep, night wakings, daytime sleep and nap frequency and duration. Using accelerometers to assess sleep in children is consistent with a handful of other paediatric studies. ${ }^{68-70}$ However, given that actigraphy has not been used extensively to measure sleep in infants and has some potential limitations,${ }^{71}$ we added additional maternal report of infant sleep duration. Mothers reported their infants' average daily sleep duration at each home visit and IVR call. Mothers completed the Children's Sleep Wake Scale ${ }^{72}$ and the Brief Infant Sleep Questionnaire $^{73}$ at each home visit.

Stress: We measured salivary cortisol as a proxy for stress in a subsample of 25 mothers and infants. Assessing cortisol in saliva is a widely accepted technique in children and adults, and researchers report a strong positive correlation between salivary and serum cortisol. ${ }^{74-76}$ Assessment via saliva has the advantage of eliminating stress introduced through blood draw and enabling mothers to collect the samples themselves for their infants at home in a more natural setting. ${ }^{77}$ Mothers collected four saliva samples from themselves and their infants over the course of 3 days (2 week days and 1 weekend day), documenting the time of day each sample was collected, and any potential problems with the collection. Mothers collected samples on waking, 30 min after waking, at 17:30 or when she retrieved her infant from childcare and at bedtime. Mothers collected infant samples by absorbing saliva from the back side of the mouth or under the tongue for $90 \mathrm{~s}$ until the swab was saturated using a SalivaBio Children's Swab (Salimetrics, State College, Pennsylvania, USA). We asked mothers to wait until after the first morning collection to feed infants, and to rinse and wipe their mouths prior to the second morning collection.

Mothers collected their own saliva samples by placing the SalivaBio swab under their tongues for $90 \mathrm{~s}$. We asked mothers to avoid lotions, makeup, toothpaste, foods and beverages prior to the collection, and to refrain from cigarette smoking and drinking alcohol. We also requested that mothers wait at least $60 \mathrm{~min}$ after eating or consuming caffeine before collecting the 17:30 or bedtime sample. We provided mothers with compliance boxes that recorded the time and date whenever the lid was opened. These compliance boxes functioned like a MEMSCap, but were larger and designed to hold the supplies needed for multiple days of saliva collection. Mothers stored the samples in home freezers until a study team member returned to retrieve and transfer them to a laboratory to be stored in a $-80^{\circ} \mathrm{C}$ freezer until being shipped in batches to the Salimetrics (Salimetrics, State College, Pennsylvania, USA) laboratory for analysis. This protocol is consistent with other studies examining changes in cortisol throughout the day for children in childcare. ${ }^{78} 79$

\section{Other measures}

We recorded medical history, pregnancy and birth outcomes via electronic medical record review, interviews and questionnaires. Infant variables of interest included race, sex and birth weight for gestational age as a continuous z-score. We collected demographic information from mothers via interviews and questionnaires at recruitment, at birth and during each home visit and IVR call. Maternal variables of interest included race, ethnicity, age, parity, education and prepregnancy BMI. We weighed mothers to the nearest $0.1 \mathrm{~kg}$ at each home visit using a Tanita BWB-800 Scale. We measured height at the first home visit only, to the nearest $0.1 \mathrm{~cm}$ using a Seca stadiometer. At enrolment and at each home visit we asked mothers to report household income, and whether they participated in the Special Supplemental Nutrition Program for Women, Infants and Children (WIC) programme during the past 3 months. Mothers completed the Healthy Home Survey ${ }^{80}$ to describe the home environment as it relates to feeding and physical activity at 6 months only. We included a number of additional measures to assess stress within the home. We measured household chaos using the Confusion, Hubbub and Order Scale (CHAOS $)^{81}$ at each home visit. Mothers also completed the Edinburgh Postnatal Depression Scale ${ }^{82}$ and the Perceived Stress Scale. ${ }^{83}$ We referred mothers to a clinician with expertise in postpartum depression if needed based on questionnaire responses. Fathers completed the Perceived Stress Scale at 6 and 12 months only. Fathers and caregivers provided demographic information (eg, race, ethnicity and age) at 6 and 12 months. Fathers also completed multiple assessments on engagement and involvement in infant caretaking $^{84}$ at 6 and 12 months.

\section{Analysis and sample size calculation}

Serial measurements collected over the course of the first year of life will allow us to address the primary aims of the study, namely to characterise temporal trends in these variables, as well as the temporal role played by the potential mediators. We will use Bayesian linear mixed models to analyse these data. ${ }^{85}{ }^{86}$ Given careful choice of the prior distribution, Bayesian methods can overcome the unreliability of likelihood-based variance components estimators. ${ }^{86}$ As most of the measurements will be collected in a serial manner, we will fit models with serially correlated, within-subject innovations; we will assume a first-order 
autoregressive (AR1) structure, but will verify robustness and goodness of fit to alternative specifications, including independence. We will investigate transformations of the adiposity measures to normality as necessary to facilitate normal theory analyses and will consider complementary summaries of the primary exposure variables, such as age-at-onset of non-parental childcare. In particular, we will fit longitudinal mixed-effects models with subjectspecific outcomes measured at 3, 6, 9, 12 months. Variables that are measured monthly through IVR calls will be averaged to create a quarterly exposure value. We will model our outcome measures of weight-for-length z-score and skinfold thicknesses separately, but will experiment with a joint model for the two outcomes. We will include important potential covariates like birth weight for gestational age z-score and breastfeeding duration in all models to help address selection bias.

To estimate power and sample size, we assumed a twosided, level 0.05 test, and estimated the power to detect a 0.09 increase in the 1-year WFL z-score for each 10-hour/ week increment spent in childcare to be 0.990 via simple linear regression modelling. We have based these estimates on our previous study of infants in childcare. ${ }^{2}$ Given that frequent, longitudinal data collection will result in less recall error and an improved ability to characterise withinsubject and between-subject variability (due to the finer scale of measurement), we anticipated even greater power to detect group differences. For purposes of these calculations, we assumed that WFL z-score is linear in time/week (TPW) (in fractions of 10-hour increments) with baseline (TPW $=0$, ie, children not in childcare) level (y-intercept) $=0.27$, slope $=0.09$ and residual $\mathrm{SD}=1.01$. Therefore, 666 (77.4\%) of the 860 infants will yield power $>90 \%$ to detect differences in WFL z-score if we are able to retain at least $85 \%$ through 12 months.

\section{FINDINGS TO DATE}

Among the 666 women included in the study, 472 $(71 \%)$ identified as black, $127(19 \%)$ as white, $7(1 \%)$ as Asian or Asian American, $6(1 \%)$ as Native American and $49(7 \%)$ as other race or more than one race; 43 (7\%) identified as Hispanic/Latina (table 1). Just under half of women $(48 \%)$ had a high school diploma or less, $61 \%$ had household incomes $<\$ 20000 /$ year and $59 \%$ were married or living with a partner. Of the 666 women, $161(24 \%)$ were food insecure in pregnancy. Three hundred and twelve women $(50 \%)$ participated in WIC during pregnancy. The mean (SD) gestational age was 41.28 weeks (2.29) and infant birth weight for gestational age $z$-score was $-0.31(0.93)$. Just under half $(49 \%)$ of infants were females, $69 \%$ received some human milk and $40 \%$ were exclusively breastfed at hospital discharge.

\section{STRENGTHS AND LIMITATIONS}

When the Nurture Study is completed, we expect to describe the relations between childcare in the first year

\begin{tabular}{|c|c|}
\hline Characteristics & Values \\
\hline Mothers' characteristics & Mean (SD) \\
\hline Age, years & $27.1(5.8)$ \\
\hline \multirow[t]{2}{*}{$\begin{array}{l}\text { Prepregnancy body mass index, } \\
\mathrm{kg} / \mathrm{m}^{2}\end{array}$} & $29.9(9.3)$ \\
\hline & Number (per cent) \\
\hline \multicolumn{2}{|l|}{ Race } \\
\hline Black & $472(71)$ \\
\hline White & $127(19)$ \\
\hline Asian/Asian American & $7(1)$ \\
\hline Native American & $6(1)$ \\
\hline Other or more than one race & $49(7)$ \\
\hline Ethnicity, Latina & $43(7)$ \\
\hline \multicolumn{2}{|l|}{ Education } \\
\hline$\leq$ High school graduate & $317(48)$ \\
\hline Some college & $239(36)$ \\
\hline College graduate & $65(10)$ \\
\hline Graduate degree & $42(6)$ \\
\hline \multicolumn{2}{|l|}{ Parity } \\
\hline 0 & $236(37)$ \\
\hline 1 & $186(29)$ \\
\hline$\geq 2$ & $216(34)$ \\
\hline \multicolumn{2}{|l|}{ Annual household income } \\
\hline$\leq \$ 20000$ & $368(61)$ \\
\hline$\$ 20001-40000$ & $126(21)$ \\
\hline$\geq \$ 40001$ & $111(18)$ \\
\hline WIC participation in pregnancy & $312(50)$ \\
\hline Infant characteristics & Mean (SD) \\
\hline Birth weight, grams & $3209.11(512.72)$ \\
\hline Birth length, centimetres & $51.12(36.64)$ \\
\hline Gestational age, weeks & $41.28(2.29)$ \\
\hline \multirow{2}{*}{$\begin{array}{l}\text { Birth weight for gestational age } \\
\text { z-score }\end{array}$} & $-0.31(0.93)$ \\
\hline & \\
\hline Sex, female & $325(49)$ \\
\hline \multicolumn{2}{|l|}{ Race } \\
\hline Black & $457(69)$ \\
\hline White & $100(15)$ \\
\hline Asian/Asian American & $3(0)$ \\
\hline Native American & $1(0)$ \\
\hline Other race & $20(3)$ \\
\hline More than one race & $75(11)$ \\
\hline Ethnicity, Latino/Latina & $59(9)$ \\
\hline Any breastfeeding at discharge & 459 (69) \\
\hline $\begin{array}{l}\text { Exclusive breastfeeding at } \\
\text { discharge }\end{array}$ & $264(40)$ \\
\hline
\end{tabular}

of life, caregivers and infant adiposity. If we find that infants in childcare or with multiple caregivers are heavier than those cared for by a parent, we also hope to identify and quantify the modifiable risk factors that mediate the relationship, and assess whether these factors differ by type and location of care, or age of care onset. Previous cohort studies have either not included sufficient representation of children from racial or ethnic minority groups, or have not asked detailed 
questions about childcare and care-giving arrangements. Additionally, we used objective measures where possible (eg, sleep and physical activity assessment) rather than relying on maternal report, to help minimise social desirability bias and recall bias. Findings from this study may have important public health and childcare implications, as they will inform policy and intervention efforts to improve this setting where the majority of US infants spend time.

Our study has some limitations. Our cohort includes a relatively low-income population of predominately black women. The demographic composition of our sample includes a higher representation of black women than the local population, and results from the study may not be directly generalisable to other populations. We may also be limited in our ability to compare findings to previous studies examining a similar research question in predominately higher income populations of women. But, our population is a priority, given the high prevalence of obesity. Additionally, $6 \%$ of infants did not meet inclusion criteria and $16.6 \%$ of women withdrew from the study or could not be reached just after delivery. Consequently, bias from loss to follow-up may be an issue. Available funding also limited our ability to collect saliva to measure maternal and infant cortisol on the entire sample. While information on the subsample may be helpful in describing the role that stress plays in the pathway between early childcare and obesity, having this information on a larger sample or on the entire sample would be ideal. However, we did not conduct a power analysis to determine whether we will be able to answer our intended research question. In fact, given the small sample size, we likely have insufficient power to analyse the cortisol data to answer the research question. All analyses we conduct will be exploratory in nature and presented with the noted limitation of sample size. Additionally, data from the cortisol assessment can provide information about the feasibility of conducting this measure in a future study. The cortisol assessment was complicated by the fact that mothers had to collect their own saliva samples and that of their infants at three different scheduled time points throughout the day over 4 days. This is a difficult task and makes compliance challenging. Feedback from mothers in the Nurture Study who collected saliva samples will help improve and refine this assessment for future studies. Finally, our sleep and physical activity assessments are based, in part, on actigraphy. While this is a highly novel approach, there are limitations and challenges associated with accelerometer data in infants. ${ }^{62}$

Obesity rates have increased globally over the past decade, even in young children. ${ }^{87-89}$ Rates of obesity are even greater in high-income countries, where childcare outside of the home is more common. ${ }^{90}{ }^{91}$ Obesity in early childhood have been linked to chronic health conditions such as diabetes mellitus and cardiovascular disease in adulthood. ${ }^{92} 93$ Even in infancy, excessive weight gain is associated with later obesity. ${ }^{94-96}$ Frequent assessments at four time points throughout infancy may help pinpoint when children begin to gain weight excessively and help identify risk factors associated with obesity. Infancy appears to be a window of opportunity for the prevention of obesity and the Nurture Study will provide important information about childcare, caregivers and weight gain throughout the first year of life.

\section{COLLABORATION}

When the proposed study is complete, we will have data on infant care-giving arrangements and childcare outside of the home, infant weight and adiposity over the first year of life, and information on the potential mediators of feeding, physical activity, sleep and stress (subsample only). Data will be available in late 2017 and may be available to other researchers interested in these variables.

\section{Author affiliations}

${ }^{1}$ Department of Health, Behavior and Society, Johns Hopkins University, Baltimore, Maryland, USA

${ }^{2}$ Department of Community and Family Medicine, Duke University Medical Center, Durham, North Carolina, USA

${ }^{3}$ Department of Psychology and Neuroscience, Duke University, Durham, North Carolina, USA

${ }^{4}$ Department of Pediatrics, Duke University Medical Center, Durham, North Carolina, USA

${ }^{5}$ Department of Statistical Science, Duke University, Durham, North Carolina, USA

${ }^{6}$ Department of Biological Sciences, North Carolina State University, Raleigh, North Carolina, USA

Contributors SEBN conceived of the study and drafted the manuscript. TØ, GGB, RMK and El contributed to the conception of the research questions and protocol and critically reviewed and provided comments on the manuscript drafts and agreed on the final submitted version. SMC and MS assisted with data collection and preparation of the table, provided comments on the manuscript draft and agreed on the final submitted version. El drafted the analysis section of the manuscript.

Funding This study was supported by a grant from the National Institutes of Health (R01DK094841).

Disclaimer The funders did not play any role in the design or conduct of the study or the interpretation and presentation of results.

Competing interests None declared.

Ethics approval The study was approved by Duke University Medical Center IRB (human subjects committee) (Pro 00036242).

Provenance and peer review Not commissioned; externally peer reviewed.

Data sharing statement The Nurture team will consider requests to use de-identified data for additional analyses related to our research questions of interest and others by outside collaborators with appropriate permissions, agreements between institutions and documentation of ethical approval.

Open Access This is an Open Access article distributed in accordance with the Creative Commons Attribution Non Commercial (CC BY-NC 4.0) license, which permits others to distribute, remix, adapt, build upon this work noncommercially, and license their derivative works on different terms, provided the original work is properly cited and the use is non-commercial. See: http:// creativecommons.org/licenses/by-nc/4.0/

\section{REFERENCES}

1. Benjamin Neelon SE, Schou Andersen C, Schmidt Morgen C, et al. Early child care and obesity at 12 months of age in the Danish National Birth Cohort. Int J Obes (Lond) 2015;39:33-8. 
2. Benjamin SE, Rifas-Shiman SL, Taveras EM, et al. Early child care and adiposity at ages 1 and 3 years. Pediatrics 2009;124:555-62.

3. Geoffroy MC, Power C, Touchette E, et al. Childcare and overweigh or obesity over 10 years of follow-up. J Pediatr 2013;162:753-58.e1.

4. Gubbels JS, Kremers SP, Stafleu A, et al. Child-care use and the association with body mass index and overweight in children from 7 months to 2 years of age. Int J Obes (Lond) 2010;34:1480-6.

5. Kim J, Peterson KE. Association of infant child care with infant feeding practices and weight gain among US infants. Arch Pediatr Adolesc Med 2008;162:627-33.

6. Lin SL, Leung GM, Hui LL, et al. Is informal child care associated with childhood obesity? Evidence from Hong Kong's "Children of 1997" birth cohort. Int J Epidemiol 2011:40:1238-46.

7. McGrady ME, Mitchell MJ, Theodore SN, et al. Preschool participation and $\mathrm{BMI}$ at kindergarten entry: the case for early behavioral intervention. $J$ Obes 2010;2010.

8. McLaren L, Zarrabi M, Dutton DJ, et al. Child care: implications for overweight / obesity in Canadian children? Chronic Dis Inj Can 2012;33:1-11

9. Pearce A, Li L, Abbas J, et al. Is childcare associated with the risk of overweight and obesity in the early years? Findings from the UK Millennium Cohort Study. Int J Obes (Lond) 2010;34:1160-8.

10. Maher EJ, Li G, Carter L, et al. Preschool child care participation and obesity at the start of kindergarten. Pediatrics 2008;122:322-30.

11. Lumeng JC, Gannon K, Appugliese D, et al. Preschool child care and risk of overweight in 6- to 12-year-old children. Int $J$ Obes (Lond) 2005;29:60-6.

12. Zahir N, Heyman MB, Wojcicki JM. No association between childcare and obesity at age 4 in low-income Latino children. Pediatr Obes 2013;8:e24-8.

13. Li B, Adab P, Cheng KK. The role of grandparents in childhood obesity in China-evidence from a mixed methods study. Int $J$ Behav Nutr Phys Act 2015;12:91.

14. Copeland KA, Benjamin Neelon SE, Howald AE, et al. Nutritional quality of meals compared to snacks in child care. Child Obes 2013;9:223-32.

15. Frampton AM, Sisson SB, Horm D, et al. What's for lunch? An analysis of lunch menus in 83 urban and rural Oklahoma child-care centers providing all-day care to preschool children. J Acad Nutr Diet 2014:114:1367-74.

16. Gubbels JS, Gerards SM, Kremers SP. Use of food practices by childcare staff and the association with dietary intake of children at childcare. Nutrients 2015;7:2161-75.

17. Gubbels JS, Raaijmakers LG, Gerards SM, et al. Dietary intake by Dutch 1- to 3-year-old children at childcare and at home. Nutrients 2014;6:304-18.

18. Maalouf J, Evers SC, Griffin M, et al. Assessment of mealtime environments and nutrition practices in child care centers in Georgia. Child Obes 2013;9:437-45.

19. Wasser HM, Thompson AL, Siega-Riz AM, et al. Who's feeding baby? Non-maternal involvement in feeding and its association with dietary intakes among infants and toddlers. Appetite 2013;71:7-15.

20. Bell AC, Finch M, Wolfenden L, et al. Child physical activity levels and associations with modifiable characteristics in centre-based childcare. Aust N Z J Public Health 2015;39:232-6.

21. Hinkley T, Carson V, Hesketh KD. Physical environments, policies and practices for physical activity and screen-based sedentary behaviour among preschoolers within child care centres in Melbourne, Australia and Kingston, Canada. Child Care Health Dev 2015;41:132-8.

22. Reilly JJ. Low levels of objectively measured physical activity in preschoolers in child care. Med Sci Sports Exerc 2010;42:502-7.

23. Rice KR, Trost SG. Physical activity levels among children attending family day care. J Nutr Educ Behav 2014;46:197-202.

24. Vanderloo LM, Tucker P, Johnson AM, et al. The influence of centre-based childcare on preschoolers' physical activity levels: a cross-sectional study. Int J Environ Res Public Health 2014;11:1794-802.

25. Ward DS. Physical activity in young children: the role of child care. Med Sci Sports Exerc 2010;42:499-501.

26. Tandon PS, Zhou C, Lozano P, et al. Preschoolers' total daily screen time at home and by type of child care. $J$ Pediatr 2011;158:297-300.

27. Vanderloo LM. Screen-viewing among preschoolers in childcare: a systematic review. BMC Pediatr 2014;14:205.

28. Hemmingsson E. A new model of the role of psychological and emotional distress in promoting obesity: conceptual review with implications for treatment and prevention. Obes Rev 2014;15:769-79.
29. Nielsen LS, Danielsen KV, Sørensen TI. Short sleep duration as a possible cause of obesity: critical analysis of the epidemiological evidence. Obes Rev 2011;12:78-92.

30. Bell JF, Zimmerman FJ. Shortened nighttime sleep duration in early life and subsequent childhood obesity. Arch Pediatr Adolesc Med 2010;164:840-5.

31. Sekine M, Yamagami T, Handa K, et al. A dose-response relationship between short sleeping hours and childhood obesity: results of the Toyama Birth Cohort Study. Child Care Health Dev 2002;28:163-70.

32. Shi Z, Taylor AW, Gill TK, et al. Short sleep duration and obesity among Australian children. BMC Public Health 2010;10:609.

33. Touchette E, Petit D, Tremblay RE, et al. Associations between sleep duration patterns and overweight/obesity at age 6 . Sleep 2008;31:1507-14.

34. von Kries R, Toschke AM, Wurmser $\mathrm{H}$, et al. Reduced risk for overweight and obesity in 5- and 6-y-old children by duration of sleep - a cross-sectional study. Int J Obes Relat Metab Disord 2002;26:710-16.

35. Acebo C, Sadeh A, Seifer R, et al. Sleep/wake patterns derived from activity monitoring and maternal report for healthy 1 - to 5 -year-old children. Sleep 2005;28:1568-77.

36. Komada $\mathrm{Y}$, Asaoka S, Abe T, et al. Relationship between napping pattern and nocturnal sleep among Japanese nursery school children. Sleep Med 2012;13:107-10.

37. Staton SL, Smith SS, Pattinson CL, et al. Mandatory naptimes in child care and children's nighttime sleep. J Dev Behav Pediatr 2015;36:235-42.

38. Thorpe K, Staton S, Sawyer E, et al. Napping, development and health from 0 to 5 years: a systematic review. Arch Dis Child 2015;100:615-22.

39. Ward TM, Gay C, Anders TF, et al. Sleep and napping patterns in 3-to-5-year old children attending full-day childcare centers. J Pediatr Psychol 2008:33:666-72.

40. Berry D, Blair C, Ursache A, et al. Child care and cortisol across early childhood: context matters. Dev Psychol 2014;50:514-25.

41. Sumner MM, Bernard K, Dozier M. Young children's full-day patterns of cortisol production on child care days. Arch Pediatr Adolesc Med 2010;164:567-71.

42. Watamura SE, Sebanc AM, Gunnar MR. Rising cortisol at childcare: relations with nap, rest, and temperament. Dev Psychobiol 2002;40:33-42.

43. Chen JH. Multiple childcare arrangements and health outcomes in early childhood. Matern Child Health J 2013;17:448-55.

44. Group WHOWMGRS. WHO child growth standards: length/ height-for-age, weight-for-age, weight-for-length, weight-for-height, and body mass index-for-age: methods and development. Geneva: World Health Organization, 2006. http://www.who.int/childgrowth/ standards/en/

45. Shorr I. How to weigh and measure children. New York: United Nations. 1986

46. de Bruin NC, van Velthoven KA, Stijnen T, et al. Body fat and fat-free mass in infants: new and classic anthropometric indexes and prediction equations compared with total-body electrical conductivity. Am J Clin Nutr 1995:61:1195-205.

47. Wells JC, Victora CG. Indices of whole-body and central adiposity for evaluating the metabolic load of obesity. Int J Obes (Lond) 2005;29:483-9.

48. Van den Broeck J, Willie D, Younger N. The World Health Organization child growth standards: expected implications for clinical and epidemiological research. Eur J Pediatr 2009;168:247-51

49. Fein SB, Labiner-Wolfe J, Shealy KR, et al. Infant Feeding Practices Study II: study methods. Pediatrics 2008;122(Suppl 2): S28-35

50. Briefel RR, Kalb LM, Condon E, et al. The Feeding Infants and Toddlers Study 2008: study design and methods. J Am Diet Assoc 2010;110(12 Suppl):S16-26.

51. Thompson AL, Mendez MA, Borja JB, et al. Development and validation of the Infant Feeding Style Questionnaire. Appetite 2009;53:210-21.

52. Blumberg SJ, Bialostosky K, Hamilton WL, et al. The effectiveness of a short form of the Household Food Security Scale. Am J Public Health 1999;89:1231-4.

53. Cook JT, Black M, Chilton M, et al. Are food insecurity's health impacts underestimated in the U.S. population? Marginal food security also predicts adverse health outcomes in young U.S. children and mothers. Adv Nutr 2013;4:51-61. 
54. Sirard JR, Trost SG, Pfeiffer KA, et al. Calibration and evaluation of an objective measure of physical activity in preschool children. $J$ Phys Act Health 2005:345-57.

55. Evenson KR, Catellier DJ, Gill K, et al. Calibration of two objective measures of physical activity for children. J Sports Sci 2008;26:1557-65.

56. Pate RR, Almeida MJ, Mclver KL, et al. Validation and calibration of an accelerometer in preschool children. Obesity (Silver Spring) 2006;14:2000-6.

57. Pate RR, Pfeiffer KA, Trost SG, et al. Physical activity among children attending preschools. Pediatrics 2004;114:1258-63.

58. Jackson DM, Reilly JJ, Kelly LA, et al. Objectively measured physical activity in a representative sample of 3- to 4-year-old children. Obes Res 2003;11:420-5.

59. Reilly JJ, Coyle J, Kelly L, et al. An objective method for measurement of sedentary behavior in 3- to 4-year olds. Obes Res 2003:11:1155-8.

60. Loprinzi PD, Fees BS, Haar S, et al. Identification of accelerometer cut-points for toddlers. Med Sci Sports Exerc 2010;45(Suppl 1):483-4.

61. Ostbye T, Zucker NL, Krause KM, et al. Kids and adults now! Defeat Obesity (KAN-DO): rationale, design and baseline characteristics. Contemp Clin Trials 2011;32:461-9.

62. Prioreschi A, Micklesfield LK. A scoping review examining physical activity measurement and levels in the first 2 years of life. Child Care Health Dev 2016:42:775-83.

63. Bayley N. The Bayley scales of infant and toddler development. In: (BSID-III) ed. 3rd edn. San Antonio, TX Psychological Corporation, 2006.

64. Benjamin Neelon SE, Oken E, Taveras EM, et al. Age of achievement of gross motor milestones in infancy and adiposity at age 3 years. Matern Child Health J 2012;16:1015-20.

65. Slining M, Adair LS, Goldman BD, et al. Infant overweight is associated with delayed motor development. J Pediatr 2010;157:20-25.e1.

66. Gartstein MA, Rothbart MK. Studying infant temperament via the Revised Infant Behavior Questionnaire. Infant Behav Dev 2003;26:64-86.

67. Rideout V. Zero to eight: children's media use in America. Common Sense Media, 2011.

68. Gregory AM, Cousins JC, Forbes EE, et al. Sleep items in the child behavior checklist: a comparison with sleep diaries, actigraphy, and polysomnography. J Am Acad Child Adolesc Psychiatry 2011;50:499-507.

69. Schwichtenberg AJ, losif AM, Goodlin-Jones B, et al. Daytime sleep patterns in preschool children with autism, developmental delay, and typical development. Am J Intellect Dev Disabil 2011;116:142-52.

70. Iwata S, Iwata O, lemura A, et al. Determinants of sleep patterns in healthy Japanese 5-year-old children. Int J Dev Neurosci 2011;29:57-62.

71. Sadeh A. The role and validity of actigraphy in sleep medicine: an update. Sleep Med Rev 2011;15:259-67.

72. LeBourgeois M, Hancock M, Harsh J R. Validation of the Children's Sleep-Wake scale (CSWS). Sleep 2003;24:A218-A19.

73. Sadeh A. A brief screening questionnaire for infant sleep problems: validation and findings for an Internet sample. Pediatrics 2004:113: e570-7.

74. Al-Ansari AA, Perry LA, Smith DS, et al. Salivary cortisol determination: adaptation of a commercial serum cortisol kit. Ann Clin Biochem 1982;19:163-6.

75. Bober JF, Weller EB, Weller RA, et al. Correlation of serum and salivary cortisol levels in prepubertal school-aged children. $J$ Am Acad Child Adolesc Psychiatry 1988;27:748-50.

76. Woodside DB, Winter K, Fisman S. Salivary cortisol in children: correlations with serum values and effect of psychotropic drug administration. Can J Psychiatry 1991;36:746-8.
77. Woolston JL, Gianfredi S, Gertner JM, et al. Salivary cortisol: a nontraumatic sampling technique for assaying cortisol dynamics. J Am Acad Child Psychiatry 1983;22:474-6.

78. Geoffroy MC, Côté SM, Parent S, et al. Daycare attendance, stress, and mental health. Can J Psychiatry 2006;51:607-15.

79. Groeneveld MG, Vermeer HJ, van IJzendoorn MH, et al. Stress, cortisol and well-being of caregivers and children in home-based child care: a case for differential susceptibility. Child Care Health Dev 2012;38:251-60.

80. Bryant MJ, Ward DS, Hales D, et al. Reliability and validity of the Healthy Home Survey: a tool to measure factors within homes hypothesized to relate to overweight in children. Int J Behav Nutr Phys Act 2008;5:23.

81. Matheny AP, Wachs TD, Ludwig JL, et al. Bringing order out of chaos: Psychometric characteristics of the confusion, hubbub, and order scale. J Appl Dev Psychol 1995;16:429-44.

82. Cox JL, Holden JM, Sagovsky R. Detection of postnatal depression. Development of the 10-item Edinburgh Postnatal Depression Scale. Br J Psychiatry 1987;150:782-6.

83. Cohen S. Perceived stress in a probability sample of the United States. In: Oskamp SSS, ed. The social psychology of health. Thousand Oaks, CA, USA: Sage Publications, Inc, 1988:31-67.

84. U.S. Department of Education NCfES. Early childhood longitudinal program birth cohort (ECLS-B). 9-month resident father self-administered questionnaire. Washington DC: National Center for Education Statistics, 2002.

85. Forni S, Gianola D, Rosa GJ. Predictive ability and covariance parameters of dynamic linear models for analysis of longitudinal traits. J Anim Sci 2009;87:3854-64.

86. Fong $\mathrm{Y}$, Rue $\mathrm{H}$, Wakefield J. Bayesian inference for generalized linear mixed models. Biostatistics 2010;11:397-412.

87. de Onis M, Blössner M, Borghi E. Global prevalence and trends of overweight and obesity among preschool children. Am J Clin Nutr 2010;92:1257-64

88. Kim J, Peterson KE, Scanlon KS, et al. Trends in overweight from 1980 through 2001 among preschool-aged children enrolled in a health maintenance organization. Obesity (Silver Spring) 2006;14:1107-12.

89. Ogden CL, Carroll MD, Lawman HG, et al. Trends in obesity prevalence among children and adolescents in the United States, 1988-1994 through 2013-2014. JAMA 2016;315:2292-9.

90. Cattaneo A, Monasta L, Stamatakis E, et al. Overweight and obesity in infants and pre-school children in the European Union: a review of existing data. Obes Rev 2010;11:389-98.

91. Wang $\mathrm{Y}$, Lim $\mathrm{H}$. The global childhood obesity epidemic and the association between socio-economic status and childhood obesity. Int Rev Psychiatry 2012;24:176-88.

92. Sovio U, Kaakinen M, Tzoulaki I, et al. How do changes in body mass index in infancy and childhood associate with cardiometabolic profile in adulthood? Findings from the Northern Finland Birth Cohort 1966 Study. Int J Obes (Lond) 2014;38:53-9.

93. Reilly JJ, Kelly J. Long-term impact of overweight and obesity in childhood and adolescence on morbidity and premature mortality in adulthood: systematic review. Int $\mathrm{J}$ Obes (Lond) 2011;35:891-8.

94. Bjerregaard LG, Rasmussen KM, Michaelsen KF, et al. Effects of body size and change in body size from infancy through childhood on body mass index in adulthood. Int $J$ Obes (Lond) 2014;38:1305-11

95. Andersen LG, Holst C, Michaelsen KF, et al. Weight and weight gain during early infancy predict childhood obesity: a case-cohort study. Int $J$ Obes (Lond) 2012;36:1306-11.

96. Taveras EM, Rifas-Shiman SL, Sherry B, et al. Crossing growth percentiles in infancy and risk of obesity in childhood. Arch Pediatr Adolesc Med 2011:165:993-8. 